\title{
Glass-Forming Ability and Mechanical Properties of Sm-Doped Fe-Cr-Mo-C-B Glassy Alloys
}

\author{
Shuhong Sheng, Chaoli Ma, Shujie Pang and Tao Zhang* \\ Department of Materials Science and Engineering, Beijing University of Aeronautics and Astronautics, Beijing 100083, P. R. China
}

\begin{abstract}
Glass-forming ability and mechanical properties of $\mathrm{Fe}_{43} \mathrm{Cr}_{16} \mathrm{Mo}_{16} \mathrm{C}_{15} \mathrm{~B}_{10 x} \mathrm{Sm}_{x}$ alloy were systematically studied in terms of the effect of substitution of rare-earth element $\mathrm{Sm}$ for the metalloid element B from 0 to 6 at\%. It was found that the thermal stability and glass-forming ability of studied alloys were greatly enhanced by the replacement of B with Sm. With merely 1 at\% Sm addition, the supercooled liquid region was extended from 66 to $88 \mathrm{~K}$, and the diameter of the cast rod with fully glassy state increased from 1.5 to $4 \mathrm{~mm}$. When the Sm content is in the range of 2 to 4 at $\%$, the critical diameter for glass formation further increased up to $5 \mathrm{~mm}$. The mechanical properties were also greatly improved by the Sm additions. The Young's modulus and compressive strength increase respectively from $140 \mathrm{GPa}$ and $2400 \mathrm{MPa}$ for the $\mathrm{Fe}_{43} \mathrm{Cr}_{16} \mathrm{Mo}_{16} \mathrm{C}_{15} \mathrm{~B}_{10}$ alloy to $189 \mathrm{GPa}$ and $3400 \mathrm{MPa}$ for the $\mathrm{Fe}_{43} \mathrm{Cr}_{16} \mathrm{Mo}_{16} \mathrm{C}_{15} \mathrm{~B}_{8} \mathrm{Sm}_{2}$ alloy. However, no improvement in plasticity was observed in the Sm-added glassy alloys. Similar to the Sm-free glassy alloys, the Sm-doped glassy alloys deformed inhomogeneously and failed in a brittle manner. The mechanism for the improved GFA by the addition of Sm is discussed.
\end{abstract}

(Received June 20, 2005; Accepted August 4, 2005; Published December 15, 2005)

Keywords: metallic glass, iron-based alloy, samarium, melt spinning, mechanical properties

\section{Introduction}

Since an amorphous structure was first obtained in the $\mathrm{Au}-$ Si system in the end of 1950 's, ${ }^{1)}$ the physics of glass-forming ability (GFA) has been one of the most important topics in the investigations of metallic glass. ${ }^{2-6)}$ Several theoretical and empirical criterions for easy glass formation have been established. They include Turnbull's 'deep eutectic' rule, ${ }^{2)}$ Egami's atomic size rule, ${ }^{3)}$ Nagel's electronic density rule ${ }^{4)}$ and Whang's thermodynamic rule $\left(\mathrm{T}_{0}\right.$ concept $){ }^{5)}$ as well as Inoue's component rule. ${ }^{6)}$ Especially, guided by Inoue's component rule, numerous bulk form metallic glasses with large sizes in all three-dimensions (generally named as bulk metallic glasses (BMGs)), have been found. ${ }^{7-11)}$

Recently, unusual glass-forming behavior has been noted in some poor glass formers with small addition of certain alloying elements. For example, the GFA was strongly enhanced by adding a small amount of rare-earth element, such as Er or Y, to Fe-based alloys, ${ }^{12-14)}$ or by adding Si to $\mathrm{Cu}$ - and Ti-based alloys. ${ }^{15-17)}$ These phenomena could not be simply interpreted by the criterions mentioned above. It is suggested that the remarkable enhancement in GFA originates mainly from two important effects. The first is the intrinsic role of the minor alloying elements in destabilizing the competing crystalline phase and stabilizing the liquid phase. ${ }^{6,13,14,18)}$ The second is that the alloying elements, such as $\mathrm{Y}$ and Er, may also act as an oxygen scavenger, which leads to the suppression of heterogeneous nucleation and, consequently, improves the GFA. ${ }^{12,19,20)}$ Though the details of the intrinsic role of the minor alloying elements in the glass former is still unclear, the fact that rare-earth elements can work as oxygen scavengers have been well known for a long time. That fluxing treatment improves the manufacturability for some Fe-based alloys ${ }^{21,22)}$ supports the second postulate and indicates that oxygen can be minimized or neutralized through alloying.

*Corresponding author, E-mail: zhangtao@buaa.edu.cn
Sm (Samarium) is a rare-earth element and has a stronger affinity for the oxygen than most transition metals. It is thus reasonably expected that $\mathrm{Sm}$ may act as an oxygen scavenger and help to suppress heterogeneous nucleations, and consequently improve the GFA of Fe-based alloys. On the other hand, $\mathrm{Sm}$ is of relatively large atomic size, which is favor to improve the GFA. ${ }^{23)} \mathrm{Fe}-\mathrm{Cr}-\mathrm{Mo}-\mathrm{C}-\mathrm{B}$ alloys are known as glass formers and a fully glass structure rod with $2.5 \mathrm{~mm}$ in diameter can be produced at $\mathrm{Fe}_{43} \mathrm{Cr}_{16} \mathrm{Mo}_{16} \mathrm{C}_{15} \mathrm{~B}_{10}$ (all alloy compositions in this paper are in atomic percent). ${ }^{24)}$ In this study, we have selected $\mathrm{Fe}_{43} \mathrm{Cr}_{16} \mathrm{Mo}_{16} \mathrm{C}_{15} \mathrm{~B}_{10}$ as the base alloy to study the effect of $\mathrm{Sm}$ addition on GFA. Because the Fe-based glassy alloys generally exhibit brittle fracture due to the existence of metalloid elements, ${ }^{25}$ ) therefore, for the purpose of simultaneously improving the GFA and modifying the mechanical properties, we introduce Sm through substitution of Sm for B in the base alloy.

\section{Experimental Procedure}

Alloy ingots with nominal compositions of $\mathrm{Fe}_{43} \mathrm{Cr}_{16}$ $\mathrm{Mo}_{16} \mathrm{C}_{15} \mathrm{~B}_{10-x} \mathrm{Sm}_{x}(x=0-6$ at $\%)$ were prepared by arc melting the mixtures of pure $\mathrm{Fe}(99.9$ mass $\%)$, Cr (99.9 mass\%), Mo (99.9 mass\%), C (99.9 mass\%), and Sm (99.9 mass\%), as well as pre-alloyed $\mathrm{Fe}_{79.5} \mathrm{~B}_{20.5}$ (99.5 mass\%) ingots in an argon atmosphere. From the obtained alloy ingots, ribbons of $\sim 0.02 \mathrm{~mm}$ thick and $1 \mathrm{~mm}$ wide were produced by a single-roller melt spinner. Bulk rod samples of about $40 \mathrm{~mm}$ long and up to $5 \mathrm{~mm}$ diameter were prepared by copper mold casting. The purity of argon gas was $99.99 \%$.

The structures of the rapidly solidified ribbon and rod specimens were examined by X-ray diffraction (XRD) using $\mathrm{Cu} K \alpha$ radiation and optical microscopy (OM). The thermal stability associated with glass transition, supercooled liquid and crystallization for the glassy alloys was investigated by differential scanning calorimetry (DSC) at a heating rate of $0.33 \mathrm{~K} / \mathrm{s}$. The compressive strength was evaluated by uniaxial compression test using specimens cut from the $3 \mathrm{~mm}$ 


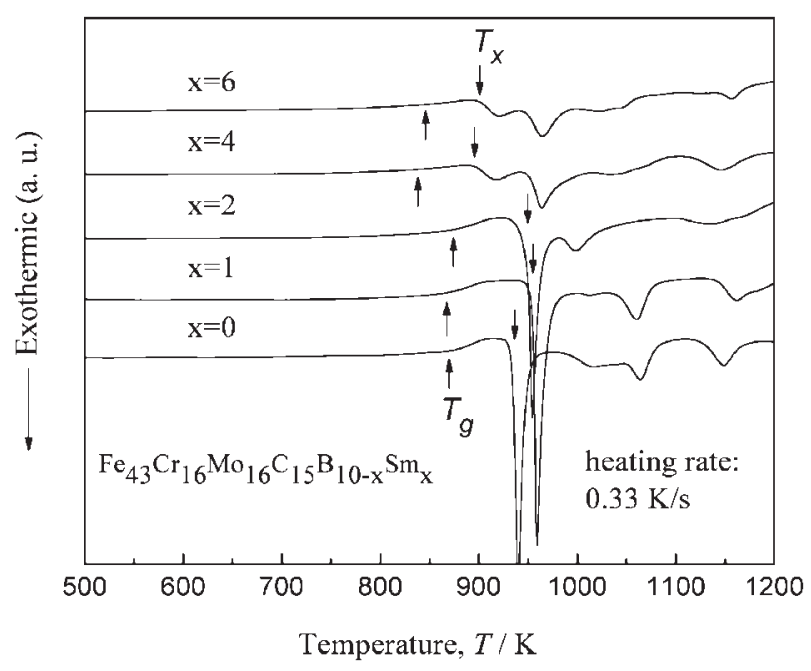

Fig. 1 DSC curves of $\mathrm{Fe}_{43} \mathrm{Cr}_{16} \mathrm{Mo}_{16} \mathrm{C}_{15} \mathrm{~B}_{10-x} \mathrm{Sm}_{x}(x=0,1,2,4,6)$ meltspun ribbons.

diameter rods. Compression tests were carried out on a SANS CMT5504 testing machine at an initial strain rate of $2.4 \times$ $10^{-4} \mathrm{~s}^{-1}$ in ambient atmosphere. Fracture surface was examined by scanning electron microscopy (SEM).

\section{Results}

\subsection{Glass forming behavior of Sm-doped $\mathrm{Fe}-\mathrm{Cr}-\mathrm{Mo}-\mathrm{C}-$ B-Sm alloys}

Melt-spun alloy ribbons were fabricated for the Smdopped alloys $\mathrm{Fe}_{43} \mathrm{Cr}_{16} \mathrm{Mo}_{16} \mathrm{C}_{15} \mathrm{~B}_{10-x} \mathrm{Sm}_{x} \quad(x=0,1,2,4,6$ at\%). XRD analysis revealed that all these ribbon samples consisted of a single glass phase. DSC analyses also confirmed their glassy nature. Figure 1 shows the DSC curves of these glassy alloy ribbons. All the samples exhibit an apparent glass transition, followed by the appearance of a supercooled liquid region and then crystallization. The glass transition temperature $\left(T_{\mathrm{g}}\right)$, onset temperature of crystallization $\left(T_{\mathrm{x}}\right)$ and supercooled liquid region $\left(\Delta T_{\mathrm{x}}=T_{\mathrm{x}}-T_{\mathrm{g}}\right)$ as a function of $\mathrm{Sm}$ content for the $\mathrm{Fe}_{43} \mathrm{Cr}_{16} \mathrm{Mo}_{16} \mathrm{C}_{15} \mathrm{~B}_{10-x} \mathrm{Sm}_{x}$ glassy alloys derived from the DSC curves are shown in Fig. 2. The $T_{\mathrm{x}}$ increases with an increase in Sm content from 0 to 1 at $\%$ and then decreases slightly with further Sm addition, while the $T_{\mathrm{g}}$ does not change distinctly. At $1 \mathrm{at} \% \mathrm{Sm}, T_{\mathrm{x}}$ has the highest value of $955 \mathrm{~K}$, which results in the highest $\Delta T_{\mathrm{x}}$ value of $88 \mathrm{~K}$. When the Sm content is more than 2 at $\%, T_{\mathrm{g}}, T_{\mathrm{x}}$ and $\Delta T_{\mathrm{x}}$ decrease apparently. At the same time, the shape of the DSC curves change greatly, suggesting the crystallization behavior is changed by the Sm additions.

Rod samples with different diameters were fabricated to evaluate the GFA of these Sm-added alloys by determining their critical diameters $\left(D_{\max }\right)$ for glass formation. As a typical example, Fig. 3 shows the XRD patterns of the cast rods with various diameters of the $\mathrm{Fe}_{43} \mathrm{Cr}_{16} \mathrm{Mo}_{16} \mathrm{C}_{15} \mathrm{~B}_{8} \mathrm{Sm}_{2}$ alloy; the data of the melt-spun alloy ribbon was also included. These XRD patterns show a broad hump, and with no evidence of crystalline phases, indicating that the meltspun ribbon and cast rods with diameters of 3 and $5 \mathrm{~mm}$ consist of mostly amorphous structure. However, some sharp

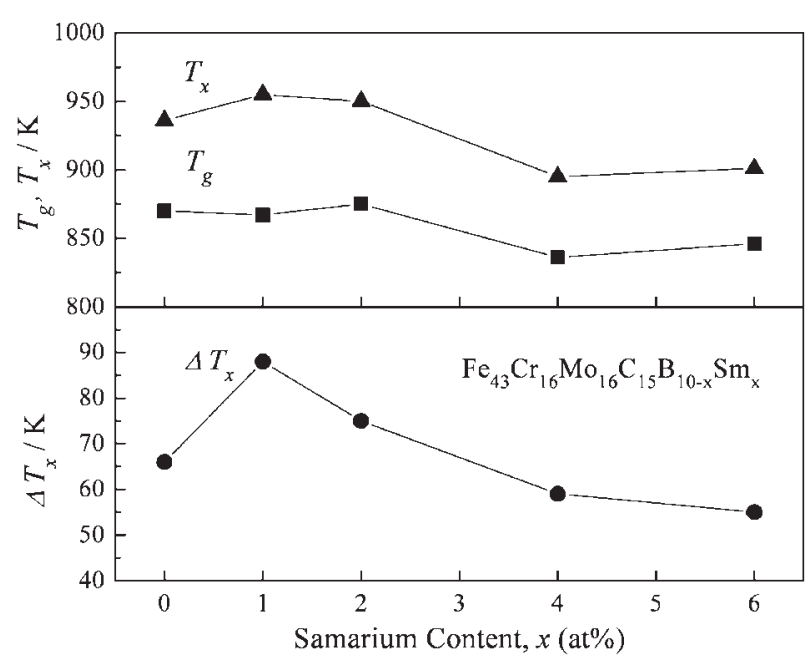

Fig. 2 Changes in $T_{\mathrm{g}}, T_{\mathrm{x}}$ and $\Delta T_{\mathrm{x}}$ with $\mathrm{Sm}$ content for the bulk glassy $\mathrm{Fe}_{43} \mathrm{Cr}_{16} \mathrm{Mo}_{16} \mathrm{C}_{15} \mathrm{~B}_{10-x} \mathrm{Sm}_{x}$.

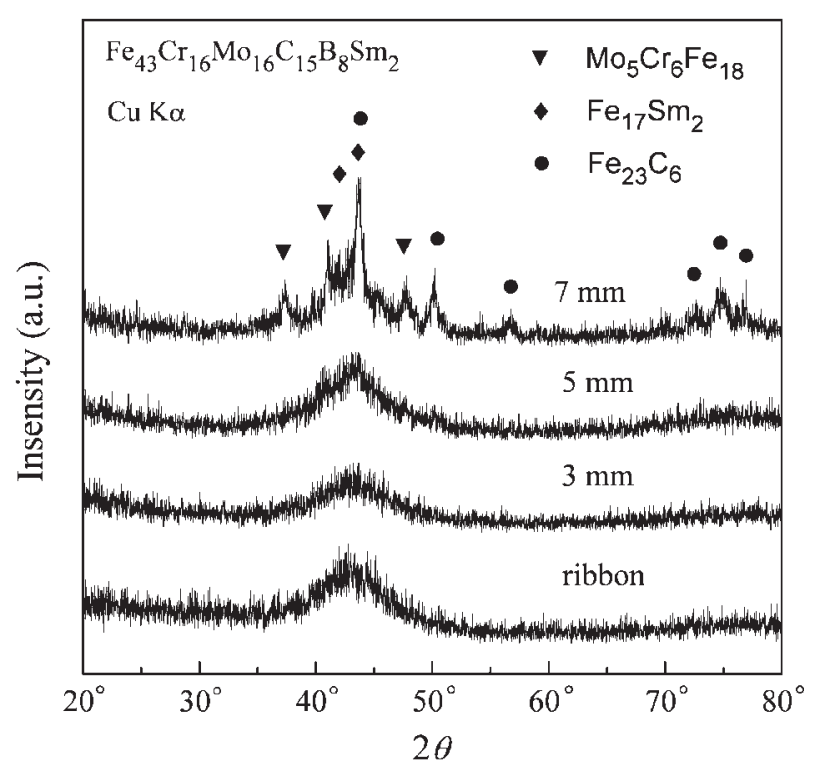

Fig. 3 XRD patterns of $\mathrm{Fe}_{43} \mathrm{Cr}_{16} \mathrm{Mo}_{16} \mathrm{C}_{15} \mathrm{~B}_{8} \mathrm{Sm}_{2}$ cast rods with different diameters.

diffraction peaks superimposed on the main hump and the background were observed for the $7 \mathrm{~mm}$ rod, suggesting partialcrystallization. The crystalline phases were identified to be $\mathrm{Mo}_{5} \mathrm{Cr}_{6} \mathrm{Fe}_{18}, \mathrm{Fe}_{17} \mathrm{Sm}_{2}$ and $\mathrm{Fe}_{23} \mathrm{C}_{6}$. Therefore, it is believed that the critical diameter for the $\mathrm{Sm}$-added $\mathrm{Fe}_{43} \mathrm{Cr}_{16} \mathrm{Mo}_{16} \mathrm{C}_{15} \mathrm{~B}_{8} \mathrm{Sm}_{2}$ alloy is between 5 and $7 \mathrm{~mm}$.

The critical diameters of the studied alloys were summarized in Table 1. The reported critical diameter for the Smfree alloy is $2.5 \mathrm{~mm}$, but in the present study only $1.5 \mathrm{~mm}$ was obtained. The presumable reason is the difference in the experimental conditions. Nevertheless, the Sm-added alloys have larger critical diameters compared to the Sm-free alloy. When the Sm content is in the range of 2 to 4 at $\%$, the critical diameter reaches $\sim 5 \mathrm{~mm}$. Figure 4(a) illustrates the surface morphology of the cast $\mathrm{Fe}_{43} \mathrm{Cr}_{16} \mathrm{Mo}_{16} \mathrm{C}_{15} \mathrm{~B}_{8} \mathrm{Sm}_{2}$ glassy alloy rods with diameters of 3 and $5 \mathrm{~mm}$. These rods display a smooth surface and metal luster. The optical micrograph of 
Table 1 Alloy compositions and thermal properties. ( $D_{\max }$ : maximum casting diameter)

\begin{tabular}{lcccc}
\hline $\begin{array}{c}\text { Alloy composition } \\
(\text { at\% })\end{array}$ & $\begin{array}{c}T_{\mathrm{g}} \\
(\mathrm{K})\end{array}$ & $\begin{array}{c}T_{\mathrm{x}} \\
(\mathrm{K})\end{array}$ & $\Delta T_{\mathrm{x}}=T_{\mathrm{x}}-T_{\mathrm{g}}$ & $\begin{array}{c}D_{\max } \\
(\mathrm{mm})\end{array}$ \\
\hline $\mathrm{Fe}_{43} \mathrm{Cr}_{16} \mathrm{Mo}_{16} \mathrm{C}_{15} \mathrm{~B}_{0}$ & 870 & 936 & 66 & 1.5 \\
$\mathrm{Fe}_{43} \mathrm{Cr}_{16} \mathrm{Mo}_{16} \mathrm{C}_{15} \mathrm{~B}_{9} \mathrm{Sm}_{1}$ & 867 & 955 & 88 & 4 \\
$\mathrm{Fe}_{43} \mathrm{Cr}_{16} \mathrm{Mo}_{16} \mathrm{C}_{15} \mathrm{~B}_{8} \mathrm{Sm}_{2}$ & 875 & 950 & 75 & 5 \\
$\mathrm{Fe}_{43} \mathrm{Cr}_{16} \mathrm{Mo}_{16} \mathrm{C}_{15} \mathrm{~B}_{6} \mathrm{Sm}_{4}$ & 836 & 895 & 59 & 5 \\
$\mathrm{Fe}_{43} \mathrm{Cr}_{16} \mathrm{Mo}_{16} \mathrm{C}_{15} \mathrm{~B}_{4} \mathrm{Sm}_{6}$ & 846 & 901 & 55 & 4 \\
\hline
\end{tabular}

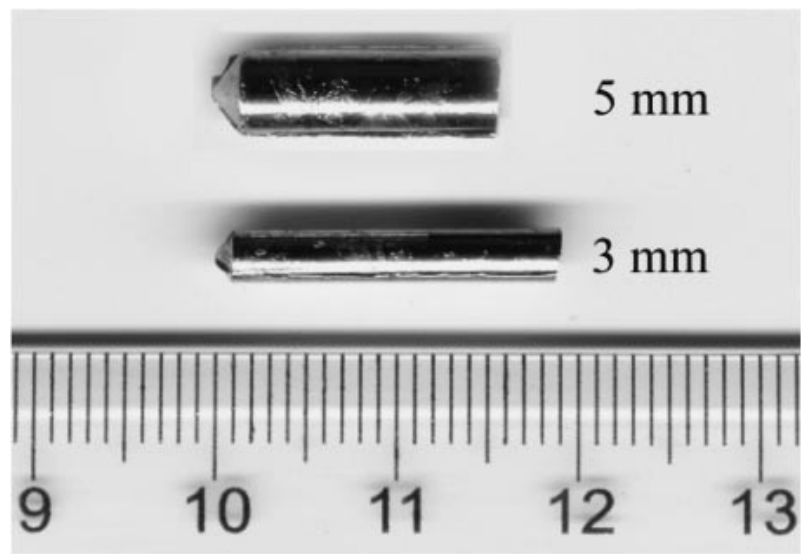

(a)

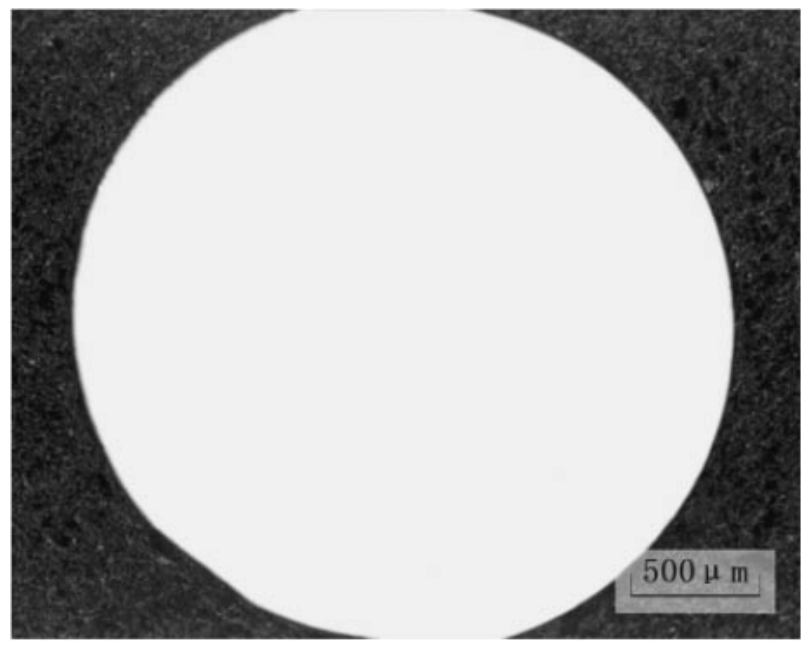

(b)

Fig. 4 (a) Outlook of cast glassy rods with diameters of 3 and $5 \mathrm{~mm}$, and (b) optical morphology of cross section of $5 \mathrm{~mm}$ rod.

the transverse cross-section [Fig. 4(b)] of $5 \mathrm{~mm}$ rods does not show any contrast from crystalline phases.

Figure 5 shows the DSC curves of the $5 \mathrm{~mm}$ $\mathrm{Fe}_{43} \mathrm{Cr}_{16} \mathrm{Mo}_{16} \mathrm{C}_{15} \mathrm{~B}_{8} \mathrm{Sm}_{2}$ glassy alloy rod, together with the data of the melt-spun alloy ribbon. It is seen that the bulk alloys exhibit distinct glass transition at $875 \mathrm{~K}$, followed by a large supercooled liquid region of $75 \mathrm{~K}$ and then crystallization at $950 \mathrm{~K}$. Furthermore, there is no appreciable difference in $T_{\mathrm{g}}$ and $T_{\mathrm{x}}$ between the cast rod and melt-spun ribbon. The heat of crystallization $\left(\Delta H_{\mathrm{x}}\right)$ for the first exothermic peak is evaluated to be $-3.6 \mathrm{~kJ} / \mathrm{mol}$ for the $5 \mathrm{~mm}$ rod and

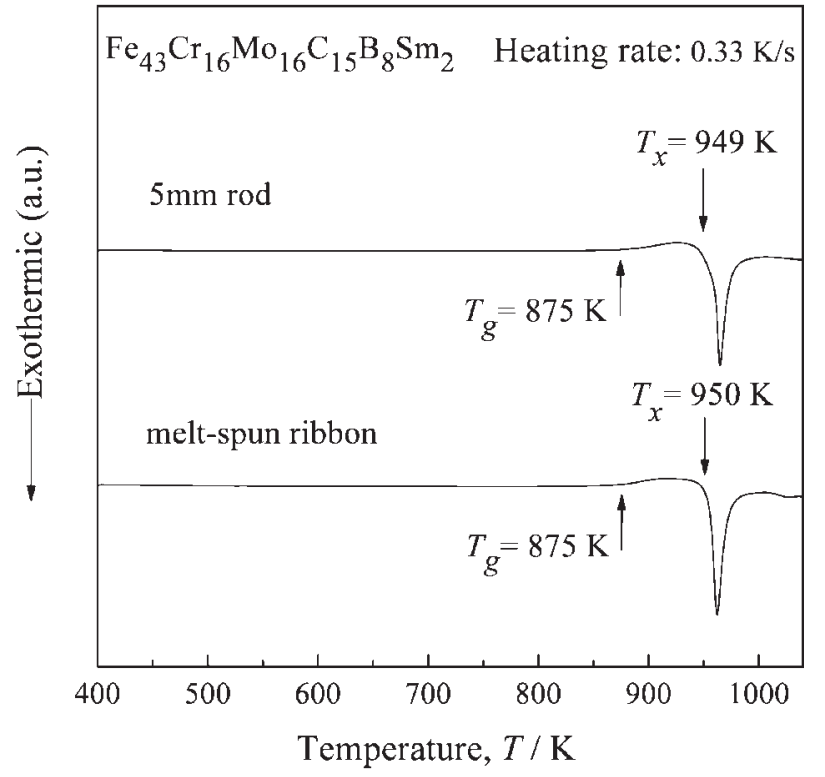

Fig. 5 DSC curves of $\mathrm{Fe}_{43} \mathrm{Cr}_{16} \mathrm{Mo}_{16} \mathrm{C}_{15} \mathrm{~B}_{8} \mathrm{Sm}_{2}$ melt-spun ribbon and glassy alloy rod with diameter of $5 \mathrm{~mm}$.

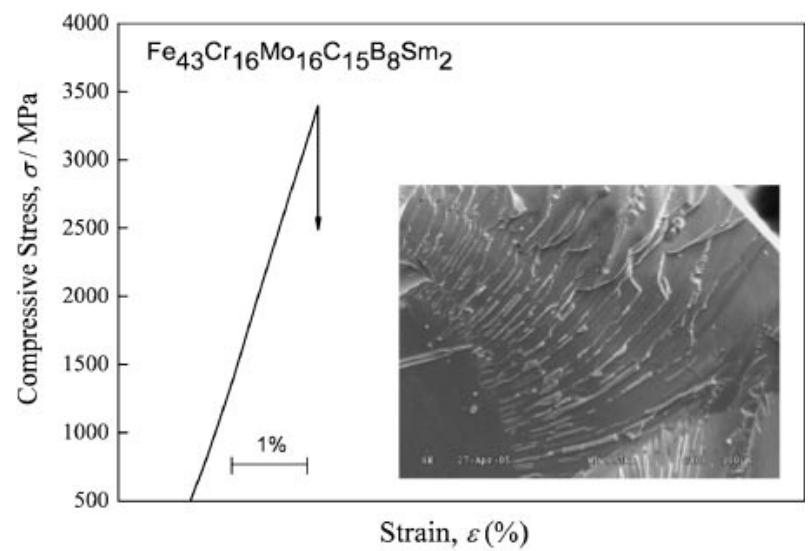

Fig. 6 Compressive stress-strain curve of $\mathrm{Fe}_{43} \mathrm{Cr}_{16} \mathrm{Mo}_{16} \mathrm{C}_{15} \mathrm{~B}_{8} \mathrm{Sm}_{2}$ amorphous alloy cylinder with diameter of $3 \mathrm{~mm}$. The insert is a SEM image showing typical fracture morphology of $\mathrm{Fe}_{43} \mathrm{Cr}_{16} \mathrm{Mo}_{16} \mathrm{C}_{15} \mathrm{~B}_{8} \mathrm{Sm}_{2}$ glass alloy.

$-3.7 \mathrm{~kJ} / \mathrm{mol}$ for the melt-spun ribbon. Here, it is worth pointing out that the $\mathrm{Sm}$ contents of the largest $D_{\max }$ value $(5 \mathrm{~mm}$ at 2 at $\% \mathrm{Sm})$ and the widest supercooled liquid region $(88 \mathrm{~K}$ at $1 \mathrm{at} \% \mathrm{Sm})$ are not the same.

\subsection{Mechanical properties}

Mechanical properties of the $3 \mathrm{~mm} \quad \mathrm{Fe}_{43} \mathrm{Cr}_{16} \mathrm{Mo}_{16}{ }^{-}$ $\mathrm{C}_{15} \mathrm{~B}_{10-x} \mathrm{Sm}_{x}$ glassy rods were measured by uni-axial compression test. Figure 6 shows the compressive stressstain curve of the bulk glassy $\mathrm{Fe}_{43} \mathrm{Cr}_{16} \mathrm{Mo}_{16} \mathrm{C}_{15} \mathrm{~B}_{8} \mathrm{Sm}_{2}$ alloy. This Sm-added alloy is subjected to elastic deformation and then fracture. The compressive strength, Young's modulus, and elastic strain are $3400 \mathrm{MPa}, 189 \mathrm{GPa}$, and $2.01 \%$, respectively. (The corresponding data for the $\mathrm{Sm}$-free alloy $\left(\mathrm{Fe}_{43} \mathrm{Cr}_{16} \mathrm{Mo}_{16} \mathrm{C}_{15} \mathrm{~B}_{10}\right)$ are $2400 \mathrm{MPa}, 140 \mathrm{GPa}$, and $1.70 \%$, respectively). It is evident that the $\mathrm{Sm}$-containing alloys have higher compressive strength than the base alloy. It should be pointed out that the compression samples crushed into small 
Table 2 Enthalpies of mixing calculated by Miedema's model ${ }^{27,28)}$ and atomic-size ratio between $\mathrm{Sm}$ and the existing components.

\begin{tabular}{ccccc}
\hline Element & $\begin{array}{c}\text { Radius } \\
(\mathrm{nm})\end{array}$ & $\begin{array}{c}\Delta H_{(\mathrm{Sm})}^{\mathrm{mix}} \\
(\mathrm{kJ} / \mathrm{mol})\end{array}$ & $R_{\mathrm{Sm}} / R_{\mathrm{A}}$ & $\left|R_{\mathrm{A}}-R_{\mathrm{Sm}}\right| / R_{\mathrm{Sm}}$ \\
\hline $\mathrm{C}$ & 0.077 & -72 & 2.338 & 0.572 \\
$\mathrm{~B}$ & 0.097 & -64 & 1.856 & 0.461 \\
$\mathrm{Cr}$ & 0.128 & 16 & 1.406 & 0.289 \\
$\mathrm{Fe}$ & 0.128 & -1 & 1.406 & 0.289 \\
$\mathrm{Mo}$ & 0.140 & 35 & 1.286 & 0.222 \\
$\mathrm{Sm}$ & 0.180 & - & 1.0 & - \\
\hline
\end{tabular}

fragments after compression test. A small amount of shear bands are seen on the side surfaces, suggesting the specimen undergoes highly localized shear deformation. A typical SEM image of fracture surface is inserted in Fig. 6. Except little amount of stages caused by rapid crack development, no typical vein-pattern is seen, suggesting a brittle failure of the Sm-added glassy alloys.

\section{Discussion}

The present results strongly suggest that the GFA of Fe$\mathrm{Cr}-\mathrm{Mo}-\mathrm{C}-\mathrm{B}$ alloys is greatly enhanced by minor alloying with $\mathrm{Sm}$. As mentioned in the introduction section, the remarkable enhancement in GFA originates from the intrinsic role of the minor alloying elements, i.e. destabilizing the competing crystalline phase, stabilizing the liquid phase, and the extrinsic role of acting as oxygen scavengers.

The detailed mechanism about the intrinsic role of the minor Sm addition is unclear. It has been suggested that the significantly different atomic size and large negative heats of mixing favor glass formation. ${ }^{3,6,26)}$ The heat of mixing calculated based on Miedema's model ${ }^{27,28)}$ and atomic radii of the components are summarized in Table 2. Sm has the largest atomic radius of $0.18 \mathrm{~nm}$ among all the constituent elements, ${ }^{29)}$ and has a large atomic size ratio with the other constituent elements. This causes large atomic mismatch, which may result in a large spectrum of atomic sizes that favors dense random atomic packing. ${ }^{23)}$ On the other hand, $\mathrm{Sm}$ has a large negative heat of mixing with $\mathrm{C}(-72 \mathrm{~kJ} / \mathrm{mol})$ and $\mathrm{B}(-64 \mathrm{~kJ} / \mathrm{mol})$, but a relatively large positive heat of mixing with $\mathrm{Cr}(16 \mathrm{~kJ} / \mathrm{mol})$ and $\mathrm{Mo}(35 \mathrm{~kJ} / \mathrm{mol}){ }^{27,28)}$ Clearly, the thermodynamic data do not satisfy the Inoue's criterion very well. But we could not rule out the possibility that some new atomic pairs among Sm, C and B are formed in supercooled liquid, which destabilize the competing crystalline phase and stabilize the liquid phase, and consequently, improve the GFA.

As for the oxygen scavenger effect of Sm, it is noted that $\mathrm{Sm}$ has a stronger affinity for the oxygen than other elements in this alloy system. The heat of forming $\mathrm{Sm}$ oxide is $-1822.6 \mathrm{~kJ} / \mathrm{mol}$, which is far higher than that of forming other oxide $\left(\mathrm{Fe}_{2} \mathrm{O}_{3},-823.4 \mathrm{~kJ} / \mathrm{mol} ; \mathrm{MoO}_{3},-745.2 \mathrm{~kJ} / \mathrm{mol}\right.$; $\left.\mathrm{Cr}_{2} \mathrm{O}_{3},-1134.7 \mathrm{~kJ} / \mathrm{mol}\right){ }^{30}$ ) The reaction between $\mathrm{Sm}$ and oxygen is thermodynamically favorable, which can alleviate the harmful effect of oxygen impurities and enhance the GFA. Similar results were reported by Liu et al. ${ }^{19)}$ and Zhang et al. $^{20)}$
Finally, it should be pointed out that the replacement of B with $\mathrm{Sm}$ in $\mathrm{Fe}-\mathrm{Cr}-\mathrm{Mo}-\mathrm{C}-\mathrm{B}-\mathrm{Sm}$ alloys greatly improve their compressive strength, but does not improve their deformation behavior, though the content of metalloid B was lowered. The understanding for the mechanism of increasing strength by Sm addition is the further research work.

\section{Conclusions}

The effect of a small addition of Sm on the glass-forming ability and mechanical properties of bulk glassy $\mathrm{Fe}_{43} \mathrm{Cr}_{16} \mathrm{Mo}_{16} \mathrm{C}_{15} \mathrm{~B}_{10 x} \mathrm{Sm}_{x}(x=0-6$ at $\%$ ) alloys was studied. It was found that the thermal stability and glass-forming ability of $\mathrm{Fe}-\mathrm{Cr}-\mathrm{Mo}-\mathrm{C}-\mathrm{B}$ alloys were greatly enhanced by the minor alloying with Sm. With merely 1 at $\%$ Sm addition, the supercooled liquid region has been extended from $66 \mathrm{~K}$ for $\mathrm{Fe}_{43} \mathrm{Cr}_{16} \mathrm{Mo}_{16} \mathrm{C}_{15} \mathrm{~B}_{10}$ alloy to $88 \mathrm{~K}$ for $\mathrm{Fe}_{43} \mathrm{Cr}_{16} \mathrm{Mo}_{16}-$ $\mathrm{C}_{15} \mathrm{~B}_{9} \mathrm{Sm}_{1}$ alloy, and the cast rod with fully glassy structure increased from $1.5 \mathrm{~mm}$ to $4 \mathrm{~mm}$ in diameter. When the $\mathrm{Sm}$ content is in the range of 2 to 4 at $\%$, the critical diameter for glass formation further increased to $5 \mathrm{~mm}$. The possible reasons for the enhancement of GFA by the minor addition of $\mathrm{Sm}$ are the intrinsic effect of $\mathrm{Sm}$ that facilitate the formation of more stable supercooled liquid and the extrinsic effect of Sm that act as an oxygen scavenger.

The mechanical properties were also greatly improved by the Sm additions. The Young's modulus and compressive strength increase respectively from $140 \mathrm{GPa}$ and $2400 \mathrm{MPa}$ for $\mathrm{Fe}_{43} \mathrm{Cr}_{16} \mathrm{Mo}_{16} \mathrm{C}_{15} \mathrm{~B}_{10}$ alloy to $189 \mathrm{GPa}$ and $3400 \mathrm{MPa}$ for $\mathrm{Fe}_{43} \mathrm{Cr}_{16} \mathrm{Mo}_{16} \mathrm{C}_{15} \mathrm{~B}_{8} \mathrm{Sm}_{2}$ alloy. But no improvement in deformation behavior was observed in the Sm-added glassy alloys. Similar to the Sm-free glassy alloys, the Sm-added glassy alloys deformed inhomogeneously and fractured brittlely.

\section{Acknowledgments}

This work was supported by the National Natural Science Foundation of China (Grant No. 50225103 and No. 50471001).

\section{REFERENCES}

1) K. Klement, R. H. Willens and P. Duwez: Nature 187 (1960) 869.

2) M. H. Cohen and D. Turnbull: Nature 189 (1961) 131-132.

3) T. Egami and Y. Waseda: J. Non-Cryst. Solids 64 (1984) 113-134.

4) S. R. Nagel and J. Tauc: Phys. Rev. Lett. 35 (1975) 380-383.

5) S. H. Whang: Mater. Sci. Eng. 57 (1983) 87-95.

6) A. Inoue: Acta Mater. 48 (2000) 279-306.

7) A. Inoue, K. Ohtera, K. Kita and T. Masumoto: Jpn. J. Appl. Phys. 27 (1988) 2248-2251.

8) A. Inoue, T. Zhang and T. Masumoto: Mater. Trans., JIM 30 (1989) 965-972.

9) T. Zhang, A. Inoue and T. Masumoto: Mater. Trans., JIM 32 (1991) 1005-1010.

10) A. Inoue and B. L. Shen: Adv. Mater. 16 (2004) 2189-2192.

11) B. L. Shen, A. Inoue and C. T. Chang: Appl. Phys. Lett. 85 (2004) 4911-4913.

12) Z. P. Lu, C. T. Liu and W. D. Porter: Appl. Phys. Lett. 83 (2003) 25812583.

13) V. Ponnambalam and S. Joseph Poon: J. Mater. Res. 19 (2004) 13201323.

14) Z. P. Lu, C. T. Liu, J. R. Thompson and W. D. Porter: Phys. Rev. Lett. 
92 (2004) $245503(1-4)$.

15) M. Hasegawa, M. Takeuchi, H. Kato and A. Inoue: Acta Mater. 52 (2004) 1799-1806.

16) H. Choi-Yim, R. Busch and W. L. Johnson: J. Appl. Phys. 83 (1998) 7993-7997.

17) C. L. Ma, S. Ishihara, H. Soejima and A. Inoue: Mater. Trans. 45 (2004) 1802-1806.

18) Z. P. Lu, C. T. Liu, C. A. Carmichael and W. D. Porter: J. Mater. Res 19 (2004) 921-929.

19) C. T. Liu, M. F. Chisholm and M. K. Miller: Intermetallics 10 (2002) 1105-1112.

20) Y. Zhang, M. X. Pan, D. Q. Zhao, R. J. Wang and W. H. Wang: Mater. Trans., JIM 41 (2000) 1410-1414.

21) T. D. Shen and R. B. Schwarz: Appl. Phys. Lett. 75 (1999) 49-51.

22) B. L. Shen, H. M. Kimura, A. Inoue and T. Mizushima: Mater. Trans.
42 (2001) 660-663.

23) O. N. Senkov and D. B. Miracle: Mater. Res. Bull. 36 (2001) 21832198.

24) S. J. Pang, T. Zhang, K. Asami and A. Inoue: J. Mater. Res. 17 (2002) 701-704.

25) H. S. Chen: Glassy Metals, Rep. Prog. Phys. 43 (1980) 353-432.

26) T. Egami: J. Non-Cryst. Solids 317 (2003) 30-33.

27) A. R. Miedema, R. Boom and F. R. De Boer: J. Less-Common Met. 41 (1975) 283.

28) A. R. Miedema and A. K. Niessen: CALPHAD 7 (1983) 27.

29) Metals Databook, ed. by Japan Inst. Metals, (Maruzen, Tokyo, 1993) p. 8.

30) O. Kubaschewski, C. B. Alock and P. J. Spencer: Materials Thermochemistry, (Pergamon Press, Oxford, New York, Seoul, Tokyo, $1993)$ pp. 258-323. 